\title{
Article \\ Adsorption of Equimolar Mixtures of Cationic and Anionic Surfactants at the Water/Hexane Interface
}

\author{
Nenad Mucic ${ }^{1, *}$, Jelena Skrbic ${ }^{1}$, Sandra Bucko ${ }^{1}$, Lidija Petrovic ${ }^{1}{ }^{10}$, Jaroslav Katona ${ }^{1, *}{ }^{\mathbb{C}}$, Valentin B. Fainerman ${ }^{2}$, \\ Eugene V. Aksenenko $^{3}{ }^{(D)}$, Emanuel Schneck ${ }^{4}(\mathbb{D})$ and Reinhard Miller ${ }^{4}(\mathbb{D}$ \\ 1 Faculty of Technology, University of Novi Sad, 21000 Novi Sad, Serbia; jelenaskrbic1994@gmail.com (J.S.); \\ sandranj@uns.ac.rs (S.B.); lidijap@uns.ac.rs (L.P.) \\ 2 SINTERFACE Technologies, D12489 Berlin, Germany; fainerman@ukr.net \\ 3 Institute of Colloid Chemistry and Chemistry of Water, National Academy of Sciences of Ukraine, \\ 03680 Kyiv, Ukraine; Eugene_Aksenenko@ukr.net \\ 4 Physics Department, Technical University Darmstadt, D64289 Darmstadt, Germany; \\ schneck@mpikg.mpg.de (E.S.); miller@fkp.tu-darmstadt.de (R.M.) \\ * Correspondence: nenad.mucic@tf.uns.ac.rs (N.M.); jaroslav.katona@uns.ac.rs (J.K.)
}

Citation: Mucic, N.; Skrbic, J.; Bucko, S.; Petrovic, L.; Katona, J.; Fainerman, V.B.; Aksenenko, E.V.; Schneck, E.; Miller, R. Adsorption of Equimolar Mixtures of Cationic and Anionic Surfactants at the Water/Hexane Interface. Colloids Interfaces 2021, 5, 1 . https://dx.doi.org/10.3390/colloids 5010001

Received: 28 November 2020 Accepted: 21 December 2020 Published: 24 December 2020

Publisher's Note: MDPI stays neutral with regard to jurisdictional claims in published maps and institutional affiliations.

Copyright: $\odot 2020$ by the authors. Licensee MDPI, Basel, Switzerland. This article is an open access article distributed under the terms and conditions of the Creative Commons Attribution (CC BY) license (https:/ / creativecommons.org/ licenses/by/4.0/).

\begin{abstract}
In mixed solutions of anionic and cationic surfactants, called catanionics, ion pairs are formed which behave like non-ionic surfactants with a much higher surface activity than the single components. In equimolar mixtures of $\mathrm{NaC}_{n} \mathrm{SO}_{4}$ and $\mathrm{C}_{\mathrm{m}} \mathrm{TAB}$, all surface-active ions are paired. For mixtures with $n+\mathrm{m}=\mathrm{const}$, the interfacial properties are rather similar. Catanionics containing one long-chain surfactant and one surfactant with medium chain length exhibit a strong increase in surface activity as compared with the single compounds. In contrast, catanionics of one mediumand one short chain surfactant have a surface activity similar to that of the medium-chain surfactant alone. Both the Frumkin model and the reorientation model describe the experimental equilibrium data equally well, while the adsorption kinetics of the mixed medium- and short-chain surfactants can be well described only with the reorientation model.
\end{abstract}

Keywords: surfactant adsorption; catanionic surfactants; water/hexane interface; interfacial tension; drop profile analysis tensiometry; effect of alkyl chain length; thermodynamic model

\section{Introduction}

Surfactants are important substances in almost every industrial technology. Detergents are made of surfactants [1], but in other applications like food processing [2], production of pharmaceuticals [3,4] or cosmetics [5] they cannot be replaced by other substances. The use of a single surfactant type is often insufficient to tailor the product properties so that mixtures of surfactants are therefore often used. With suitable formulations, various interfacial properties can be optimized.

When surfactants are mixed, their interfacial behaviour can be predicted from the interfacial properties of the single components. In [6] a thermodynamic model was derived to describe the equilibrium adsorption layer characteristics of mixtures of non-ionic surfactants with other surfactants, ionic or non-ionic. Also, the adsorption kinetics of mixed surfactant solutions was studied and a generalized Frumkin model was proposed. When coupled with the theory for diffusion-controlled adsorption proposed by Ward and Tordai [7], a quantitative analysis of dynamic interfacial tension data can be performed [8].

However, when anionic and cationic surfactants are mixed, the resulting interfacial characteristics cannot be simply derived from the properties of the single compounds. In aqueous solution of anionic and cationic surfactants, ion pairs are formed which behave like non-ionic surfactants [9]. Although the respective bulk mixtures were extensively investigated many years ago [10,11], the properties of the resulting interfacial adsorption layers, such as their foam stabilizing capabilities, cannot be predicted from the bulk behavior alone [12]. These paired surfactants are, however, of great interest, because they are 
effectively double-tailed (and therefore lipid-like) surface active molecules and suitable for numerous applications in pharmacy [4], drug delivery [13,14], vesicle formation $[15,16]$ or cosmetics [17] and can be combined with ionic liquids [18,19]. A systematic study of catanionics adsorbed at liquid interfaces is therefore of great importance.

Recently, we have studied catanionic solutions at the water/air and water/hexane interface and described the adsorption layers of equimolar mixtures of sodium dodecyl sulphate $\left(\mathrm{NaC}_{12} \mathrm{SO}_{4}\right)$ and dodecyl trimethylammonium bromide $\left(\mathrm{C}_{12} \mathrm{TAB}\right)$, having identical chain lengths. The formed ion pairs showed a much higher surface activity than the single surfactants, i.e., the corresponding interfacial tension isotherm was shifted to lower bulk concentrations by a factor of about 1000. Moreover, the adsorption layer characteristics were different for the two interfaces, in particular the molar area of the adsorbed ion pairs.

The aim of the present work is to determine the interfacial activity of catanionics formed by surfactants with unequal chain lengths, i.e., we investigate sodium alkyl sulphates $\left(\mathrm{NaC}_{\mathrm{n}} \mathrm{SO}_{4}\right)$ and alkyl trimethylammonium bromides $\mathrm{C}_{\mathrm{n}} \mathrm{TAB}$ with short $\left(\mathrm{C}_{6}\right)$, medium $\left(\mathrm{C}_{12}\right)$ and long $\left(\mathrm{C}_{16}\right)$ alkyl chains.

\section{Materials and Methods}

$\mathrm{NaC}_{6} \mathrm{SO}_{4}$ (sodium hexyl sulphate, $\mathrm{Mw}=204.22 \mathrm{~g} / \mathrm{mol}$ ), $\mathrm{NaC}_{12} \mathrm{SO}_{4}$ (sodium dodecyl sulphate, $\mathrm{Mw}=288.37 \mathrm{~g} / \mathrm{mol}$ ), $\mathrm{NaC}_{16} \mathrm{SO} 4$ (sodium hexadecyl sulphate, $\mathrm{Mw}=344.5 \mathrm{~g} / \mathrm{mol}$ ), $\mathrm{C}_{6} \mathrm{TAB}$ (hexyl trimethylammonium bromide, $\mathrm{MW}=224.18 \mathrm{~g} / \mathrm{mol}$ ), $\mathrm{C}_{12} \mathrm{TAB}$ (dodecyl trimethylammonium bromide, $\mathrm{Mw}=308.35 \mathrm{~g} / \mathrm{mol}$ ), and $\mathrm{C}_{16} \mathrm{TAB}$ (hexadecyl trimethylammonium bromide, $\mathrm{Mw}=364.45 \mathrm{~g} / \mathrm{mol}$ ) were purchased from Fluka (Buchs, Switzerland). The samples had a purity of $>99 \%$ and were used as received. All solutions were prepared with ultrapure Milli-Q water (with a resistivity of $18.2 \mathrm{M} \Omega \mathrm{cm}$ ). Hexane was purchased from Fluka, distilled, purified with alumina, and subsequently saturated with ultrapure Milli-Q water. The positively and negatively charged surfactants were mixed in an equimolar ratio.

The experiments were performed with the Drop Profile Analysis Tensiometer PAT-1 (SINTERFACE Technologies, Berlin, Germany). The experimental details have been published in detail earlier [20]. The experiments at the solution/oil interface were performed with drops of pure hexane in a glass cuvette filled with the aqueous solution. The dynamic interfacial tension was measured for different concentrations of the surfactants mixtures at the solution/hexane interfaces. The measured equilibrium and dynamic interfacial tension values were used to construct the equilibrium adsorption isotherms and kinetic adsorption dependencies, respectively. The times necessary to obtain the whole kinetic adsorption curves, as well as the interfacial tension equilibriums, for all measurements were longer than one hour. The interfacial tension at $25^{\circ} \mathrm{C}$ for the pure water/air and pure water/hexane interfaces are $72.0 \mathrm{mN} / \mathrm{m}$ and $51.1 \mathrm{mN} / \mathrm{m}$, respectively, in agreement with the literature [21].

\section{Theory}

Recently, the adsorption layer behavior of aqueous surfactant solutions at water/oil interfaces was described by a thermodynamic model based on the competitive adsorption of surfactant and oil molecules [22]. Here, we deal with solutions of equimolar binary surfactant mixtures so that we have potentially three components in the interfacial layer (two surfactants and the oil molecules). Therefore, we decided to use a simpler thermodynamic model, which considers the adsorption of the surfactant molecules at the interface while the oil molecules are passively embedded in the oleophilic moiety of the surfactant adsorption layers. Hence, we use two classical adsorption models, the one developed by Frumkin [23] and the reorientation model proposed by Fainerman et al. [24]. Via a best fit procedure, the experimental equilibrium and kinetic interfacial tension data were directly compared with the calculated data and thus the values for the characteristic parameters for the two theoretical models obtained. 
The equation of state (1) and adsorption isotherm (2) for the common Frumkin adsorption model are given by:

$$
\begin{gathered}
\Pi=-\frac{\mathrm{RT}}{\omega_{0}}\left[\ln (1-\theta)+\alpha \theta^{2}\right] \\
\mathrm{bc}=\frac{\theta}{1-\theta} \exp (-2 \alpha \theta)
\end{gathered}
$$

Here $\Pi$ is the interfacial pressure defined as the difference between interfacial tension values for the pure solvent $\gamma_{0}$ (water/hexane) and the solution $\gamma$ (aqueous solution/hexane). The partial surfactant molar area is given by $\omega$ having the value $\omega_{0}$ at $\Pi=0$. Further quantities in the model Equations (1) and (2) are the intermolecular interaction parameter $\mathrm{a}$, the adsorption equilibrium parameter $\mathrm{b}$ and the surfactant bulk concentration $\mathrm{c}$. The interfacial layer coverage $\theta(0 \leq \theta<1)$ results from the adsorbed amount of surfactant $\Gamma$ and the corresponding molar area $\omega$. Finally, $R$ and $T$ are the gas law constant and the absolute temperature, respectively. It was assumed in [25] that the surfactant molar area $\omega$ can be presented as a function of the interfacial pressure $\Pi$ (Equation (3)):

$$
\omega=\omega_{0}(1-\varepsilon \Pi \theta)
$$

with $\varepsilon$ being the intrinsic compressibility coefficient of the adsorbed molecules.

The equation of state for the adsorption layer based on the reorientation model (surfactant molecules can adsorb in two orientations) has the following form (Equation (4)) [24]:

$$
-\frac{\Pi \omega_{0}}{\mathrm{RT}}=\ln (1-\Gamma \omega)+\Gamma\left(\omega-\omega_{0}\right)+\mathrm{a}(\Gamma \omega)^{2}
$$

For its derivation, the non-ideality of enthalpy and entropy of mixing were assumed. Here the average molar area results as an average of the two orientations, $\omega=$ $\left(\omega_{1} \Gamma_{1}+\omega_{2} \Gamma_{2}\right) / \Gamma$, with the total surface coverage of $\theta=\omega \Gamma=\omega_{1} \Gamma_{1}+\omega_{2} \Gamma_{2}=\theta_{1}+\theta_{2}$, and the total adsorption $\Gamma=\Gamma_{1}+\Gamma_{2}$. The two orientation states are characterized by the molar areas $\omega_{1}$ and $\omega_{2}\left(\omega_{1}<\omega_{2}\right)$. Note, for this reorientation model the intrinsic compressibility is essential only for the adsorption in state 1 with the minimum molar area: $\omega_{1}=\omega_{10}(1-\varepsilon \Pi \theta)$. The corresponding adsorption isotherm reads (Equation (5)):

$$
b_{1} c=\frac{\Gamma_{1} \omega_{0}}{(1-\Gamma \omega)^{\omega_{1} / \omega_{0}}} \exp \left(-2 a \theta \frac{\omega_{1}}{\omega_{0}}\right)
$$

In [24] it was also shown that the adsorption activity coefficients for molecules adsorbed in the two states obey the relation $b_{2} / b_{1}=\left(\omega_{2} / \omega_{1}\right)^{\alpha}$ with the exponent $\alpha$ as an additional model parameter.

We also analyzed the dynamic interfacial tensions, i.e., the kinetics of adsorption of the surfactant molecules at the water/hexane interface. For a diffusion-controlled adsorption, the adsorption process at a liquid spherical interface can be described by the Ward-Tordai equation in the form (Equation (6)) [26]:

$$
\Gamma(t)=\sqrt{\frac{4 D}{\pi}}\left[c_{0} \sqrt{t}-\int_{0}^{\sqrt{t}} c_{s}(t-\tau) d \sqrt{\tau}\right] \pm \frac{D}{r}\left[c_{0} t-\int_{0}^{t} c_{s}(t-\tau) d \tau\right]
$$

where $t$ is the time, $c_{0}$ is the surfactant bulk concentration and $c_{s}$ the so-called subsurface concentration, related to the adsorption isotherm, Equation (2) or (5). The parameter $r$ defines the droplet radius, $\mathrm{D}$ is the surfactant diffusion coefficient. The sign \pm in Equation (6) corresponds to adsorption from outside the drop (+) or from inside the drop (-). Algorithms suitable for a numerical solution of Equation (6) were discussed for example in [27]. 


\section{Results and Discussion}

As shown previously [28-30], two oppositely charged surfactants dissolved in pure water form ion pairs, in the following also called dimers. Such dimers can show much higher surface activity than the single surfactants. Their molecular geometry, i.e., the chain lengths of the two surfactants directly influences the dimer's surface activity. In the present work, we investigated catanionic surfactants with a medium chain length $\left(\mathrm{C}_{12}\right)$ mixed with surfactants having a long $\left(\mathrm{C}_{16}\right)$ or a short $\left(\mathrm{C}_{6}\right)$ alkyl chain, respectively.

\subsection{Equilibrium Interfacial Tension Isotherms}

As shown in Figure 1, the equilibrium adsorption isotherms of the two equimolar mixtures $\left[\mathrm{NaC}_{12} \mathrm{SO}_{4}+\mathrm{C}_{16} \mathrm{TAB}\right]$ and $\left[\mathrm{NaC}_{16} \mathrm{SO}_{4}+\mathrm{C}_{12} \mathrm{TAB}\right]$ are almost identical, although these two catanionics have different constituents. The reason lays in the similar geometry of the formed dimers, i.e., both dimers possess one positive and one negative charge accompanied with one $\mathrm{C}_{12}$ and one $\mathrm{C}_{16}$ chain (total of 28 carbon atoms in the alkyl chains).

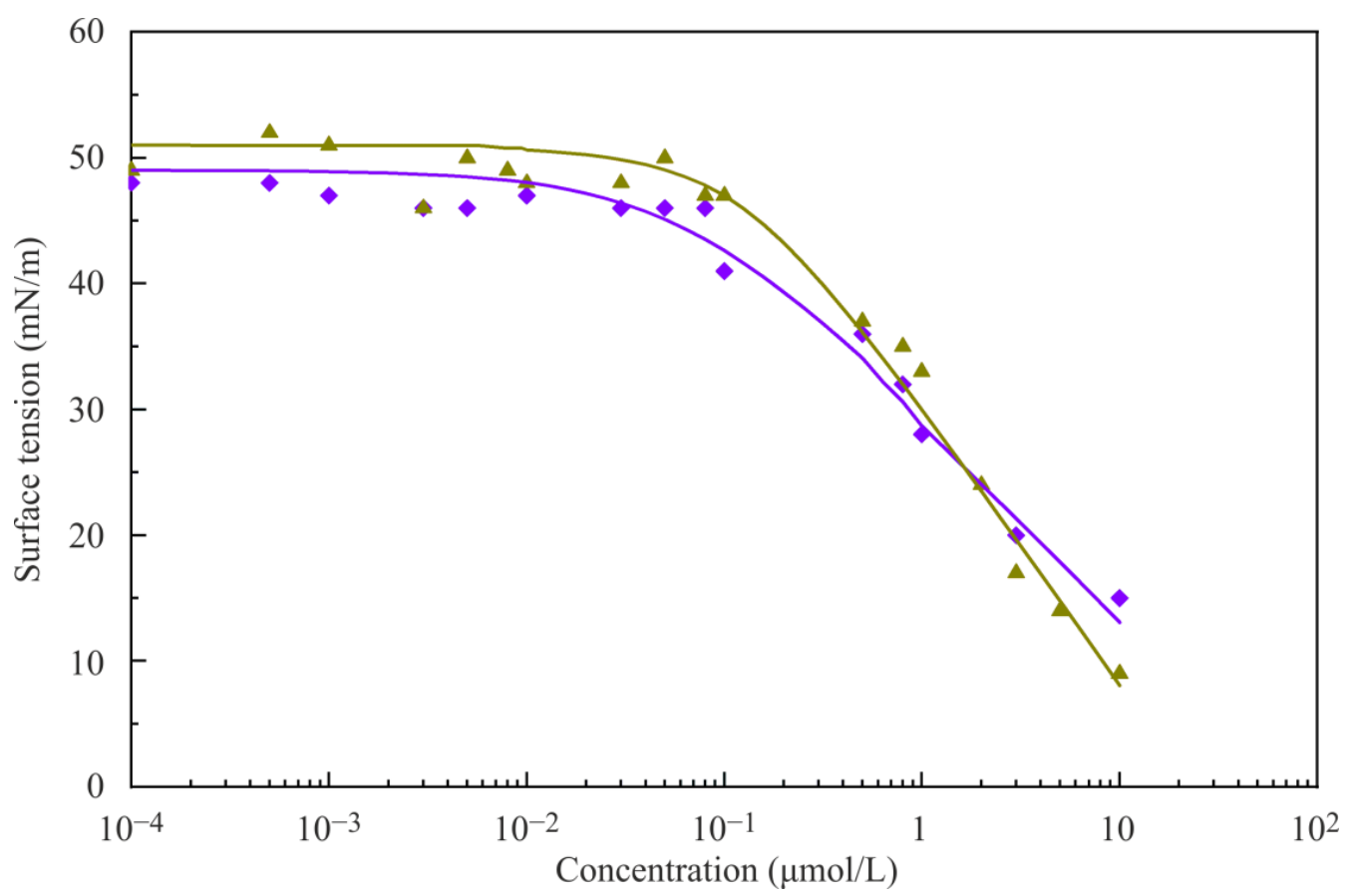

Figure 1. Equilibrium interfacial tension measured by profile analysis tensiometry (PAT) at the solution/hexane interface as a function of the total bulk concentration c of the mixtures: $(\bullet) \mathrm{NaC}_{12} \mathrm{SO}_{4}+$ $\mathrm{C}_{16} \mathrm{TAB}$ and $(\Delta) \mathrm{NaC}_{16} \mathrm{SO}_{4}+\mathrm{C}_{12} \mathrm{TAB}$; the solid lines are the fitting results for a Frumkin adsorption model given by Equations (1)-(3).

In Figure 2, the adsorption isotherms of mixtures of $\left[\mathrm{NaC}_{12} \mathrm{SO}_{4}+\mathrm{C}_{6} \mathrm{TAB}\right]$ and $\left[\mathrm{NaC}_{6} \mathrm{SO}_{4}+\mathrm{C}_{12} \mathrm{TAB}\right]$ are shown. Here we have a total of 18 carbon atoms in the alkyl chains, and again visually identical isotherms are obtained, i.e., the two resulting dimers exhibit similar surface activities.

Fitting the experimental results in Figures 1 and 2 with the Frumkin model, we obtain the results summarized in Tables 1 and 2. Although the values of the fitting parameters show slight differences, the shapes of the adsorption isotherm curves shown in Figures 1 and 2, respectively, are quite similar. 


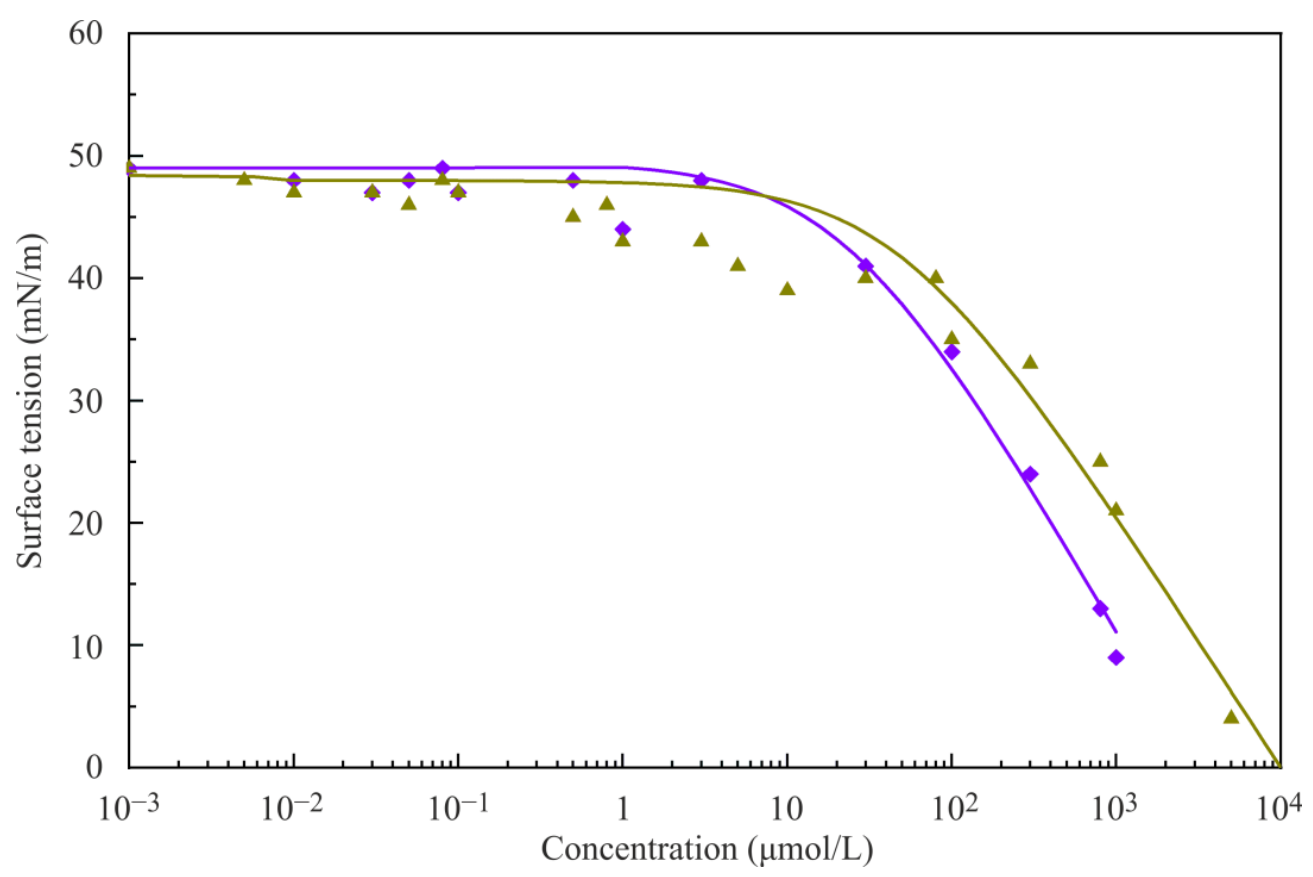

Figure 2. Equilibrium interfacial tension measured by profile analysis tensiometry (PAT) at the solution/hexane interface as a function of the total bulk concentration c of mixtures: $(\bullet) \mathrm{NaC}_{12} \mathrm{SO}_{4}$ $+\mathrm{C}_{6} \mathrm{TAB}$ and $(\Delta) \mathrm{NaC}_{6} \mathrm{SO}_{4}+\mathrm{C}_{12} \mathrm{TAB}$; the solid lines are the fitting results for a Frumkin adsorption model given by Equations (1)-(3).

Table 1. Parameter values obtained by fitting the Frumkin adsorption model Equations (1)-(3) to the experimental data of Figure 1.

\begin{tabular}{ccccc}
\hline System & $\mathbf{b}\left[\mathbf{m}^{3} / \mathbf{m o l}\right]$ & $\boldsymbol{\omega}_{\mathbf{0}}\left[\mathbf{m}^{2} / \mathbf{m o l}\right]$ & $\mathbf{a}$ & $\varepsilon[\mathbf{m} / \mathbf{m N}]$ \\
\hline $\mathrm{NaC}_{12} \mathrm{SO}_{4}+\mathrm{C}_{16} \mathrm{TAB}$ & $1.30 \times 10^{4}$ & $3.50 \times 10^{5}$ & 0 & 0.005 \\
$\mathrm{NaC}_{16} \mathrm{SO}_{4}+\mathrm{C}_{12} \mathrm{TAB}$ & $3.85 \times 10^{3}$ & $2.50 \times 10^{5}$ & 0.75 & 0.005 \\
\hline
\end{tabular}

Table 2. Parameter values obtained by fitting the Frumkin adsorption model Equations (1)-(3) to the experimental data of Figure 2.

\begin{tabular}{ccccc}
\hline System & $\mathbf{b}\left[\mathbf{m}^{3} / \mathbf{m o l}\right]$ & $\boldsymbol{\omega}_{\mathbf{0}}\left[\mathbf{m}^{2} / \mathbf{m o l}\right]$ & $\mathbf{a}$ & $\varepsilon[\mathbf{m} / \mathbf{m N}]$ \\
\hline $\mathrm{NaC}_{12} \mathrm{SO}_{4}+\mathrm{C}_{6} \mathrm{TAB}$ & $4.30 \times 10^{1}$ & $2.40 \times 10^{5}$ & 0 & 0.005 \\
$\mathrm{NaC}_{6} \mathrm{SO}_{4}+\mathrm{C}_{12} \mathrm{TAB}$ & $2.03 \times 10^{1}$ & $2.70 \times 10^{5}$ & 0 & 0.005 \\
\hline
\end{tabular}

In Figure 3, the adsorption isotherm for the mixture $\left(\mathrm{NaC}_{12} \mathrm{SO}_{4}+\mathrm{C}_{16} \mathrm{TAB}\right)$ is plotted together with the isotherms of the single surfactants $\mathrm{NaC}_{12} \mathrm{SO}_{4}$ and $\mathrm{C}_{16} \mathrm{TAB}$, respectively. The resulting dimers show a much higher surface activity, i.e., the adsorption isotherm is remarkably shifted to lower bulk concentrations, i.e., the dimers have a surface activity one order of magnitude higher than that of the long chain compound $\mathrm{C}_{16} \mathrm{TAB}$ and 3 orders of magnitude higher than that of the medium chain surfactant $\mathrm{NaC}_{12} \mathrm{SO}_{4}$. Here we take the adsorption equilibrium coefficient $b$ in the Frumkin isotherm as a measure for the surface activity (see Table 3). 


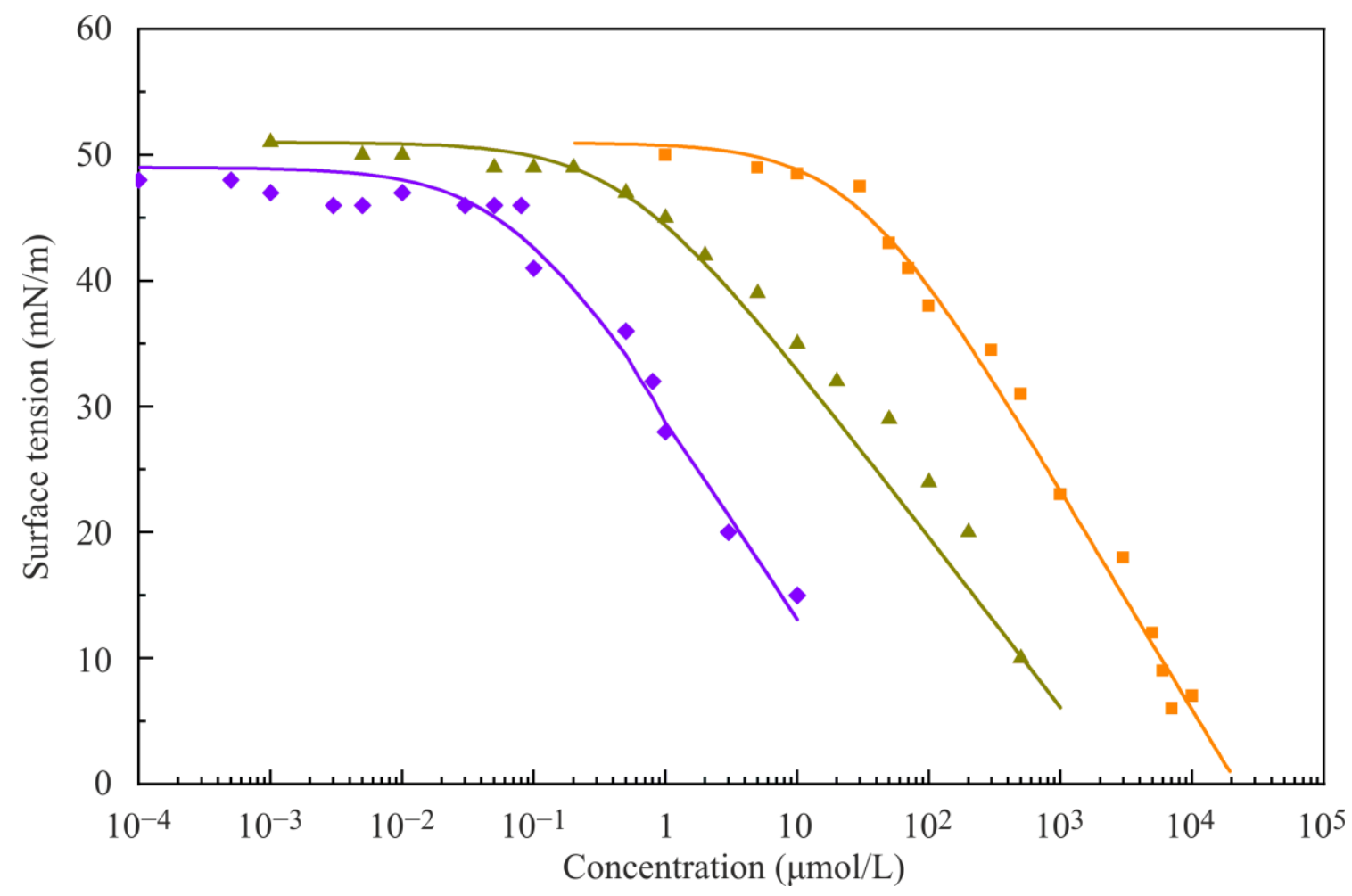

Figure 3. Equilibrium interfacial tension measured by profile analysis tensiometry (PAT) at the solution/hexane interface as a function of the total bulk concentration c of the mixtures $(\diamond) \mathrm{NaC}_{12} \mathrm{SO}_{4}+\mathrm{C}_{16} \mathrm{TAB}$ and the individual surfactants ( $\square$ ) $\mathrm{NaC}_{12} \mathrm{SO}_{4}$ and $(\boldsymbol{\Delta}) \mathrm{C}_{16} \mathrm{TAB}$; the solid lines are the fitting results for a Frumkin adsorption model given by Equations (1)-(3).

Table 3. Parameter values obtained by fitting the Frumkin adsorption model Equations (1)-(3) to the experimental data of Figure 3.

\begin{tabular}{ccccc}
\hline System & $\mathbf{b}\left[\mathbf{m}^{3} / \mathbf{m o l}\right]$ & $\boldsymbol{\omega}_{\mathbf{0}}\left[\mathbf{m}^{2} / \mathbf{m o l}\right]$ & $\mathbf{a}$ & $\varepsilon[\mathbf{m} / \mathbf{m n}]$ \\
\hline $\mathrm{NaC}_{12} \mathrm{SO}_{4}+\mathrm{C}_{16} \mathrm{TAB}$ & $1.50 \times 10^{4}$ & $3.50 \times 10^{5}$ & 0 & 0.005 \\
$\mathrm{NaC}_{12} \mathrm{SO}_{4}$ & $3.11 \times 10^{1}$ & $6.31 \times 10^{5}$ & 0.1 & 0.005 \\
$\mathrm{C}_{16} \mathrm{TAB}$ & $2.08 \times 10^{3}$ & $4.50 \times 10^{5}$ & 0 & 0.005 \\
\hline
\end{tabular}

Similar to Figure 3, in Figure 4 the isotherm of $\mathrm{NaC}_{16} \mathrm{SO}_{4}+\mathrm{C}_{12} \mathrm{TAB}$ is plotted together with the isotherms of the single surfactants $\mathrm{NaC}_{16} \mathrm{SO}_{4}$ and $\mathrm{C}_{12} \mathrm{TAB}$, respectively. The adsorption isotherm of the ion pair is shifted toward lower bulk concentrations in the same way as for the surfactant mixture shown in Figure 3 and the change in the surface activity of the dimer, as compared to the two compounds, is quite similar to these finding, as we can see from the $b$ values given in Table 4 . 


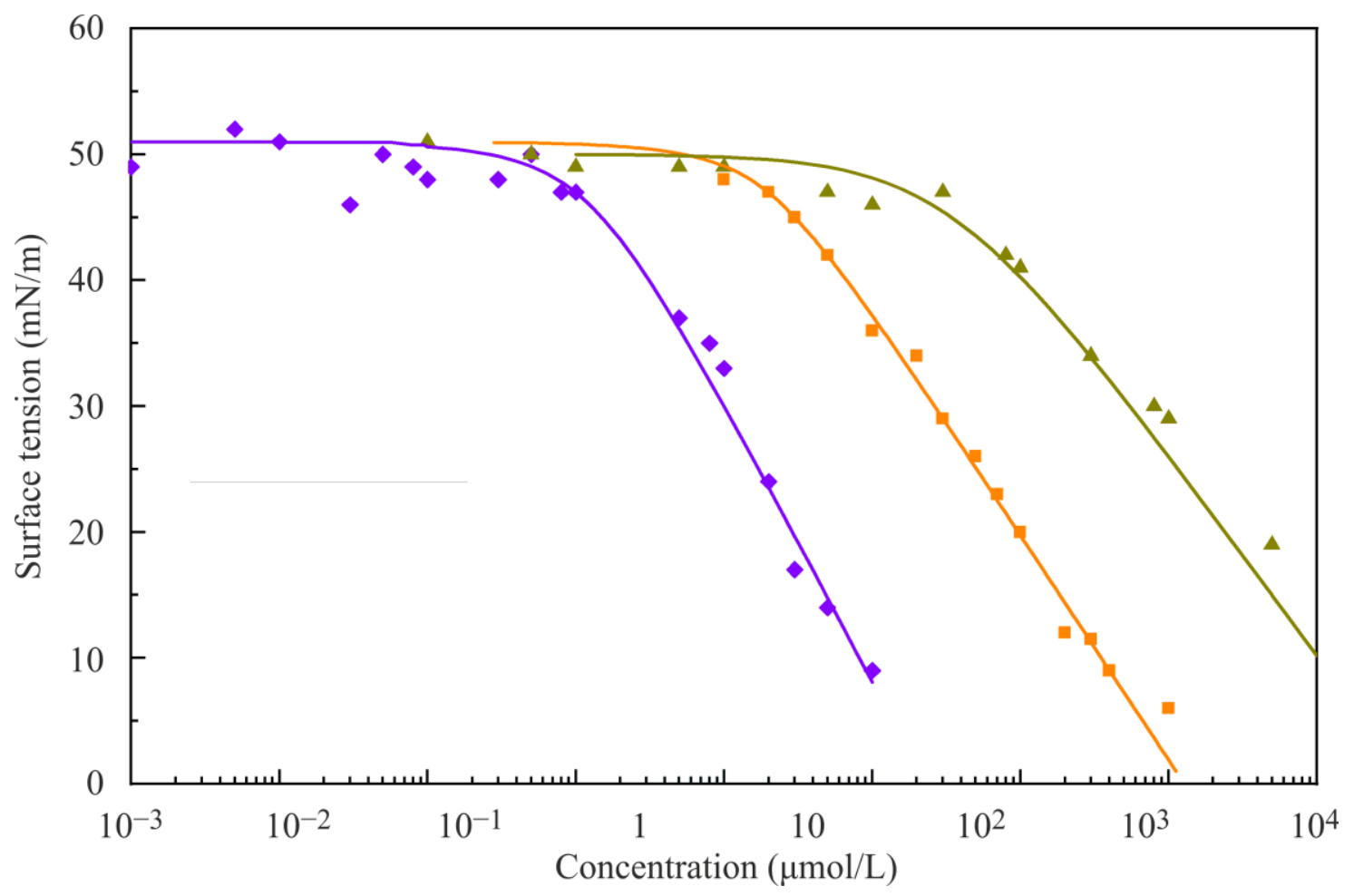

Figure 4. Equilibrium interfacial tension measured by profile analysis tensiometry (PAT) at the solution/hexane interface as a function of the total bulk concentration c of the mixtures $(\diamond) \mathrm{NaC}_{16} \mathrm{SO}_{4}+\mathrm{C}_{12} \mathrm{TAB}$ and the individual surfactants ( $\square$ ) $\mathrm{NaC}_{16} \mathrm{SO}_{4}$ and $(\Delta) \mathrm{C}_{12} \mathrm{TAB}$; the solid lines are the fitting results for a Frumkin adsorption model given by Equations (1)-(3).

Table 4. Parameter values obtained by fitting the Frumkin adsorption model Equations (1)-(3) to the experimental data of Figure 4.

\begin{tabular}{ccccc}
\hline System & $\mathbf{b}\left[\mathbf{m}^{3} / \mathbf{m o l}\right]$ & $\boldsymbol{\omega}_{\mathbf{0}}\left[\mathbf{m}^{2} / \mathbf{m o l}\right]$ & $\mathbf{a}$ & $\varepsilon[\mathbf{m} / \mathbf{m N}]$ \\
\hline $\mathrm{NaC}_{16} \mathrm{SO}_{4}+\mathrm{C}_{12} \mathrm{TAB}$ & $3.85 \times 10^{3}$ & $2.50 \times 10^{5}$ & 0.75 & 0.005 \\
$\mathrm{NaC}_{16} \mathrm{SO}_{4}$ & $2.26 \times 10^{2}$ & $6.31 \times 10^{5}$ & 0.86 & 0.005 \\
$\mathrm{C}_{12} \mathrm{TAB}$ & $3.06 \times 10^{1}$ & $3.55 \times 10^{5}$ & 0 & 0.005 \\
\hline
\end{tabular}

In contrast to Figures 3 and 4 , when mixing medium chain surfactants $\left(C_{12}\right)$ with short chain surfactants $\left(\mathrm{C}_{6}\right)$, the resulting adsorption isotherm for the dimer is positioned close to the isotherm for the medium chain surfactant (Figure 5). In other words, the adsorption activity of the complexes is not significantly increased in comparison to the activity of the single medium chain surfactant (values of the model parameters are summarized in Table 5).

Table 5. Parameter values obtained by fitting the Frumkin adsorption model Equations (1)-(3) to the experimental data of Figure 5.

\begin{tabular}{ccccc}
\hline System & $\mathbf{b}\left[\mathbf{m}^{3} / \mathbf{m o l}\right]$ & $\boldsymbol{\omega}_{\mathbf{0}}\left[\mathbf{m}^{2} / \mathbf{m o l}\right]$ & $\mathbf{a}$ & $\varepsilon[\mathbf{m} / \mathbf{m N}]$ \\
\hline $\mathrm{NaC}_{12} \mathrm{SO}_{4}+\mathrm{C}_{6} \mathrm{TAB}$ & $4.30 \times 10^{1}$ & $2.40 \times 10^{5}$ & 0 & 0.005 \\
$\mathrm{NaC}_{12} \mathrm{SO}_{4}$ & $3.11 \times 10^{1}$ & $6.31 \times 10^{5}$ & 0.10 & 0.005 \\
$\mathrm{C}_{6} \mathrm{TAB}$ & $2.48 \times 10^{-1}$ & $4.45 \times 10^{5}$ & 0 & 0.005 \\
\hline
\end{tabular}




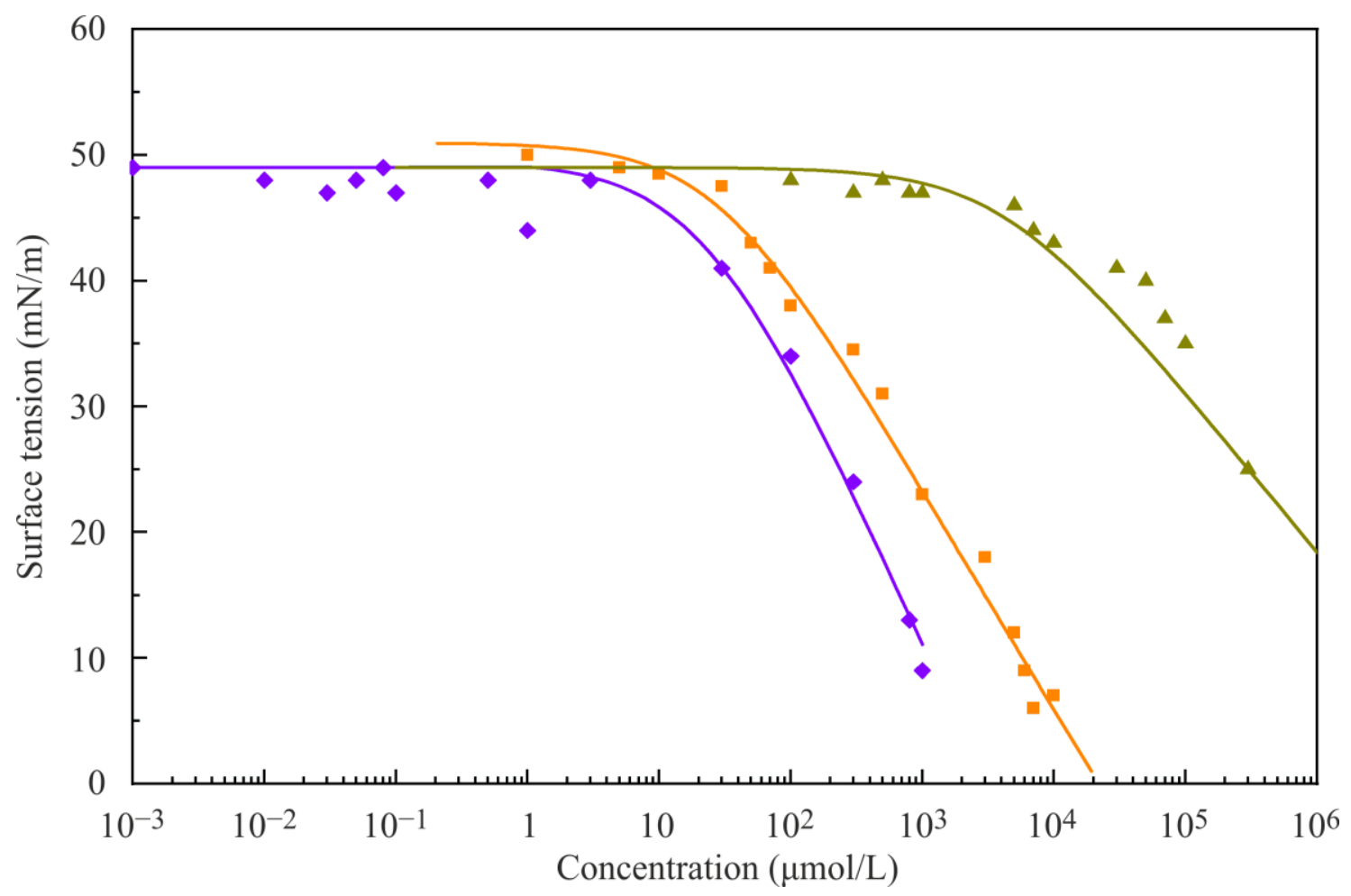

Figure 5. Equilibrium interfacial tension measured by profile analysis tensiometry (PAT) at the solution/hexane interface as a function of the total bulk concentration c of the mixtures $(\diamond) \mathrm{NaC}_{12} \mathrm{SO}_{4}+\mathrm{C}_{6} \mathrm{TAB}$ and the individual surfactants ( $\square$ ) $\mathrm{NaC}_{12} \mathrm{SO}_{4}$ and $(\Delta) \mathrm{C}_{6} \mathrm{TAB}$; the solid lines are the fitting results for a Frumkin adsorption model given by Equations (1)-(3).

$\mathrm{C}_{6} \mathrm{TAB}$ possesses a positively charged ionic group and a short $\mathrm{C}_{6}$ alkyl chain. Thus, the solubility of such molecule in water is preferable as compared with the hydrophobic interaction with other surfactants or oil molecules at the interface. As shown in Figure 5 the adsorption isotherms of the $\left[\mathrm{NaC}_{12} \mathrm{SO}_{4}+\mathrm{C}_{6} \mathrm{TAB}\right]$ mixture and the single $\mathrm{NaC}_{12} \mathrm{SO}_{4}$ are similar because the adsorption layer consists mainly of $\mathrm{NaC}_{12} \mathrm{SO}_{4}$ molecules. It was shown in [30] that by mixing long chain surfactants with short alkyl chain molecules, the short chains are removed from the adsorption layer by mutual interaction between the long chains of the surfactants. Similarly, in this work, the short chain surfactant $\mathrm{C}_{6} \mathrm{TAB}$ is probably squeezed out from the mixed adsorption layer by the much longer chains of the $\mathrm{NaC}_{12} \mathrm{SO}_{4}$ molecules.

Similarly to Figure 5, in Figure 6 the adsorption isotherms of single surfactants and ion pairs of $\mathrm{NaC}_{6} \mathrm{SO}_{4}$ and $\mathrm{C}_{12} \mathrm{TAB}$, respectively, are shown. Due to the rather high price for the substance and the large amount needed for experiments, the $\mathrm{NaC}_{6} \mathrm{SO}_{4}$ adsorption isotherm (shown in Figure 6 by a dashed line) was not experimentally measured but rather extrapolated via Traube's rule [31]. $\mathrm{NaC}_{6} \mathrm{SO}_{4}$ as single surfactant shows low surface activity as compared to $\mathrm{C}_{12} \mathrm{TAB}$ and their mixtures $\mathrm{NaC}_{6} \mathrm{SO}_{4}+\mathrm{C}_{12} \mathrm{TAB}$. Thus, $\mathrm{NaC}_{6} \mathrm{SO}_{4}$ does not significantly influence the total surface activity of the dimer $\mathrm{NaC}_{6} \mathrm{SO}_{4}+\mathrm{C}_{12} \mathrm{TAB}$. Therefore, the dimer adsorption isotherm has a similar shape and position like the isotherm for the single $\mathrm{C}_{12} \mathrm{TAB}$ (values of model parameters are summarized in Table 6). 


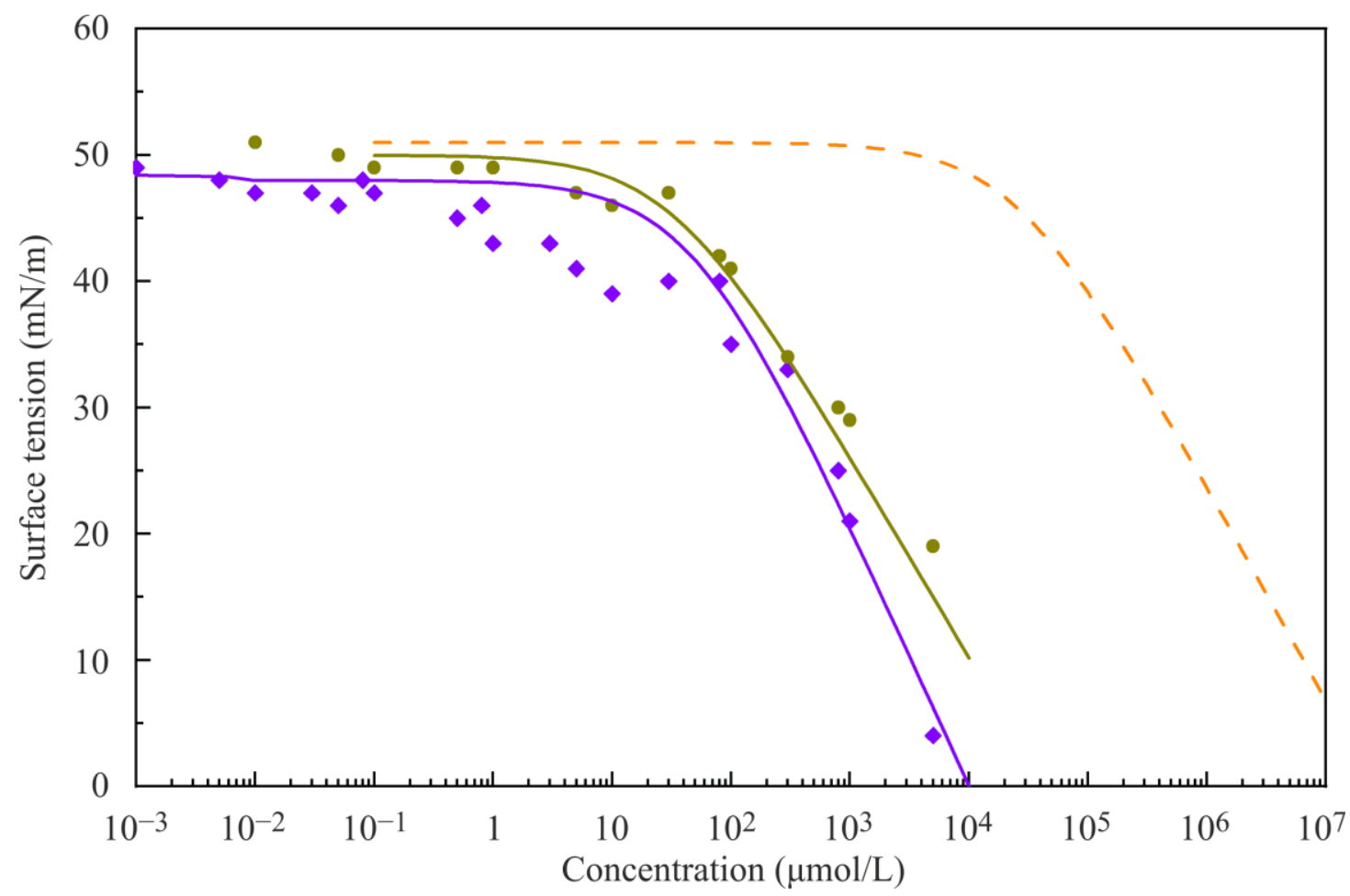

Figure 6. Equilibrium interfacial tension measured by profile analysis tensiometry (PAT) at the solution/hexane interface as a function of the total bulk concentration $c$ of the mixtures $(\diamond) \mathrm{NaC}_{6} \mathrm{SO}_{4}+\mathrm{C}_{12} \mathrm{TAB}$ and the individual surfactant $(\bullet)$ $\mathrm{C}_{12} \mathrm{TAB}$. The solid lines are the fitting results for a Frumkin adsorption model given by Equations (1)-(3); the dashed line (---) was obtained by calculations using the parameters for $\mathrm{NaC}_{6} \mathrm{SO}_{4}$ listed in Table 6 and almost coincide with the values estimated by Traube's rule.

Table 6. Parameter values obtained by fitting the Frumkin adsorption model Equations (1)-(3) to the experimental data of Figure 6.

\begin{tabular}{ccccc}
\hline System & $\mathbf{b}\left[\mathbf{m}^{3} / \mathbf{m o l}\right]$ & $\boldsymbol{\omega}_{\mathbf{0}}\left[\mathbf{m}^{2} / \mathbf{m o l}\right]$ & $\mathbf{a}$ & $\varepsilon[\mathbf{m} / \mathbf{m N}]$ \\
\hline $\mathrm{NaC}_{6} \mathrm{SO}_{4}+\mathrm{C}_{12} \mathrm{TAB}$ & $2.03 \times 10^{1}$ & $2.70 \times 10^{5}$ & 0 & 0.005 \\
$\mathrm{NaC}_{6} \mathrm{SO}_{4}$ & $4.00 \times 10^{-2}$ & $3.35 \times 10^{5}$ & 0 & 0.005 \\
$\mathrm{C}_{12} \mathrm{TAB}$ & $3.06 \times 10^{1}$ & $3.55 \times 10^{5}$ & 0 & 0.005 \\
\hline
\end{tabular}

\subsection{Dynamic Interfacial Tensions}

After the equilibrium adsorption isotherms are determined and discussed, we now discuss the adsorption kinetics results in terms of dynamic interfacial tensions. The kinetic curves are fitted with the reorientation and Frumkin models, respectively. Since the measured solutions present mixtures of single surfactants and of complexes, i.e., cationics, anionics and catanionics, the Frumkin model does not always fit sufficiently well the catanionic combinations while the reorientation model describes the measured dependencies much better.

In Figure 7 the dynamic interfacial tensions of $\left[\mathrm{NaC}_{16} \mathrm{SO}_{4}+\mathrm{C}_{12} \mathrm{TAB}\right]$ mixtures show relatively slow adsorption kinetics at concentrations close to adsorption saturation $(5 \mu \mathrm{mol} / \mathrm{L}$ and $10 \mu \mathrm{mol} / \mathrm{L}$ ). The interfacial tension decrease starts at about $100 \mathrm{~s}$ and reaches the equilibrium after about $3 \mathrm{~h}\left(10^{4} \mathrm{~s}\right)$. However, the interfacial tension decrease is significant, $\Delta \gamma>40 \mathrm{mN} / \mathrm{m}$. Thus, the dimers $\mathrm{NaC}_{16} \mathrm{SO}_{4}+\mathrm{C}_{12} \mathrm{TAB}$ in comparison with its single surfactants [32] show much slower adsorption kinetics but the same interfacial effect, i.e., the same interfacial pressure. 


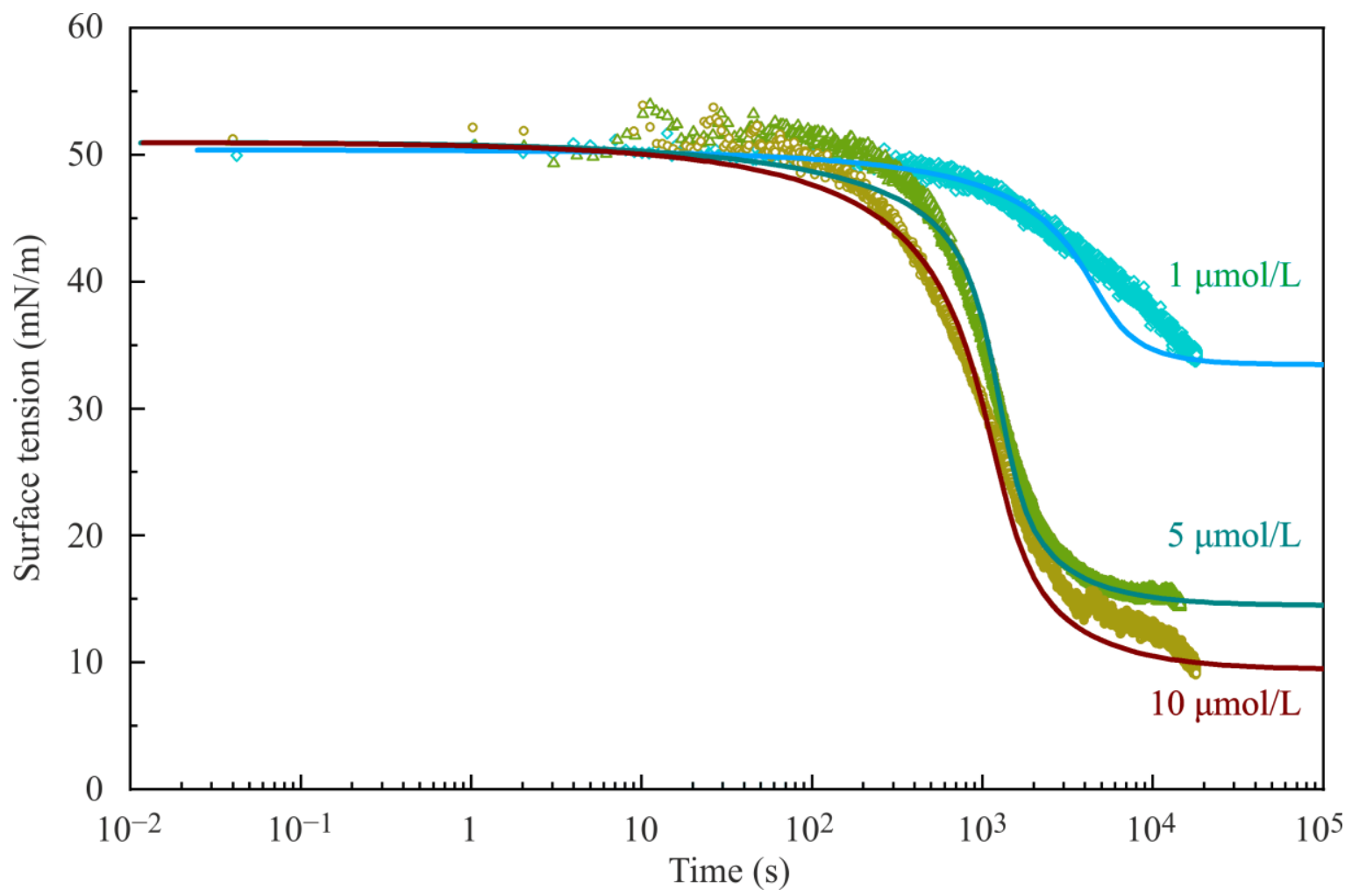

Figure 7. Dynamic interfacial tension of mixed aqueous solutions of $\mathrm{NaC}_{16} \mathrm{SO}_{4}+\mathrm{C}_{12} \mathrm{TAB}$ at the water/hexane interface measured by PAT-1; $(\diamond) 1 \mu \mathrm{mol} / \mathrm{L},(\Delta) 5 \mu \mathrm{mol} / \mathrm{L},(\bullet) 10 \mu \mathrm{mol} / \mathrm{L}$; solid lines are calculated from the Frumkin adsorption model; the same data and the corresponding fitted curves for the reorientation model are shown in the supplement materials.

The curves in Figure 7 are fitted with the Frumkin model (see also Figure S1 in the Supplementary Materials). Due to the relatively simple curve shapes, both models show similar fitting quality. Table 7 and also Table S1 in the Supplement summarize the model parameters. Note, however, that for a better fitting of dynamic dependencies, the parameters $\omega_{0}$ and a should be slightly adjusted as compared to those used for fitting the isotherm. With thus corrected values of the model parameters, we can calculate the adsorption isotherms shown in Figure 1 with almost the same quality.

Table 7. Parameter values obtained by fitting the Frumkin adsorption model Equations (1)-(3) and the diffusion Equation (6) to the experimental data of Figure 7 as measured for equimolar solutions of $\mathrm{NaC}_{16} \mathrm{SO}_{4}+\mathrm{C}_{12} \mathrm{TAB}$.

\begin{tabular}{cccccc}
\hline $\mathbf{c}[\mathbf{m o l} / \mathbf{L}]$ & $\mathbf{b}\left[\mathbf{m}^{\mathbf{3}} / \mathbf{m o l}\right]$ & $\boldsymbol{\omega}_{\mathbf{0}}\left[\mathrm{m}^{2} / \mathbf{m o l}\right]$ & $\mathbf{a}$ & $\varepsilon[\mathbf{m} / \mathbf{m N}]$ & $\mathbf{D}\left[\mathbf{m}^{2} / \mathbf{s}\right]$ \\
\hline $1.00 \times 10^{-6}$ & $3.85 \times 10^{3}$ & $2.85 \times 10^{5}$ & 0.60 & 0.005 & $5.00 \times 10^{-10}$ \\
$5.00 \times 10^{-6}$ & $3.85 \times 10^{3}$ & $2.55 \times 10^{5}$ & 0.80 & 0.005 & $2.40 \times 10^{-10}$ \\
$1.00 \times 10^{-5}$ & $3.85 \times 10^{3}$ & $2.30 \times 10^{5}$ & 0.20 & 0.005 & $1.00 \times 10^{-10}$ \\
\hline
\end{tabular}

The kinetics obtained for $\mathrm{NaC}_{12} \mathrm{SO}_{4}+\mathrm{C}_{16} \mathrm{TAB}$ equimolar solutions are shown in Figure 8. As for the $\mathrm{NaC}_{16} \mathrm{SO}_{4}+\mathrm{C}_{12} \mathrm{TAB}$ mixtures in Figure 7, the curves display significant interfacial tension decrease and slow adsorption kinetics. Since the number of methylene groups per dimer is the same for both mixtures, they exhibit a similar kinetic behavior. The kinetic data in Figure 8 were also fitted with the two adsorption models, and both show good agreement with the experimental data. 


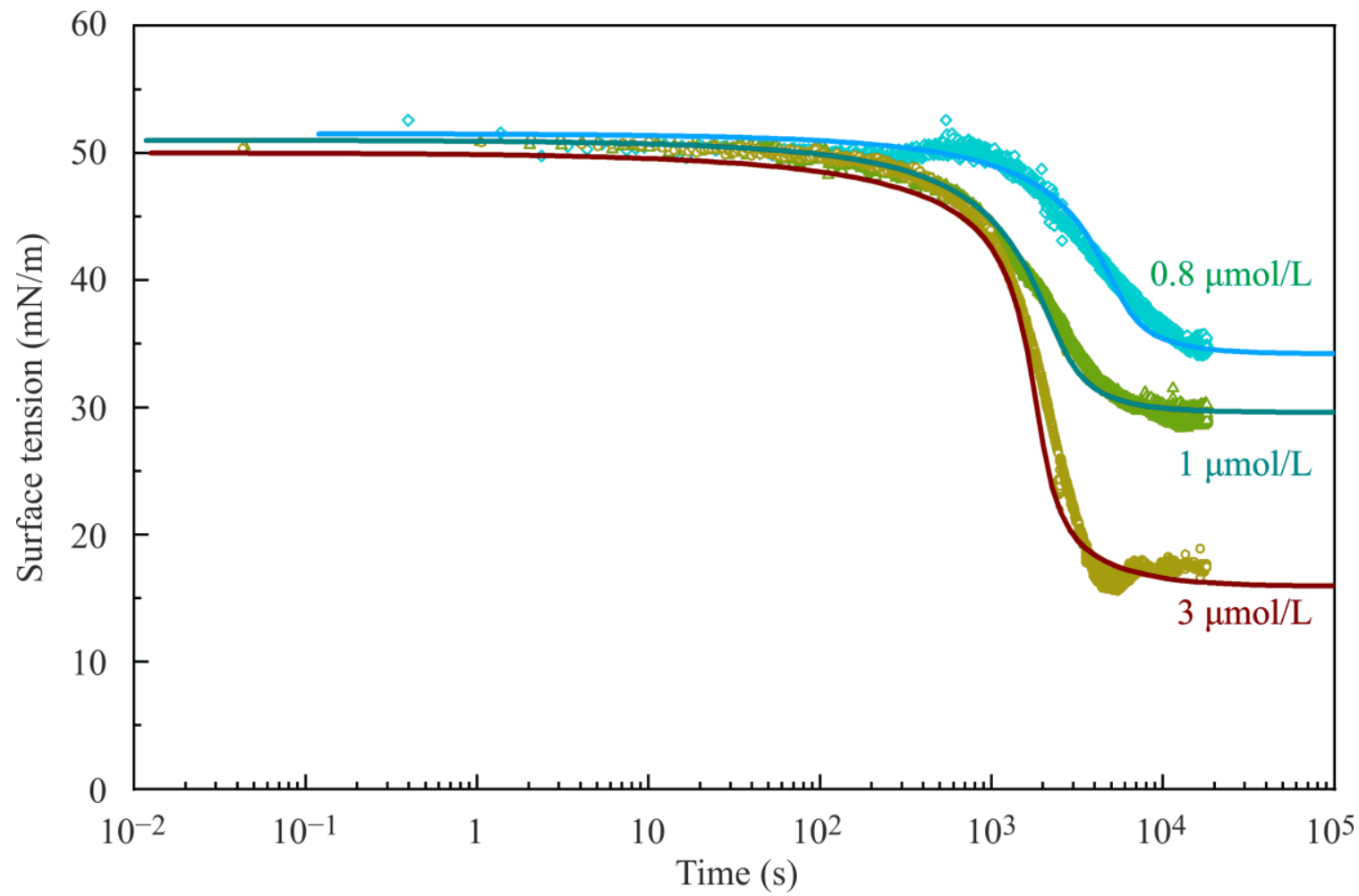

Figure 8. Dynamic interfacial tension of mixed aqueous solutions of $\mathrm{NaC}_{12} \mathrm{SO}_{4}+\mathrm{C}_{16} \mathrm{TAB}$ at the water/hexane interface measured by PAT-1; $(\diamond) 0.8 \mu \mathrm{mol} / \mathrm{L},(\Delta) 1 \mu \mathrm{mol} / \mathrm{L},(\bullet) 3 \mu \mathrm{mol} / \mathrm{L}$; solid lines are calculated from the Frumkin adsorption model; the same data and the corresponding fitted curves for the reorientation model are shown in the supplement materials.

The parameters obtained for the Frumkin and reorientation models are listed in Table 8 and Table S2 (see Supplementary Materials), respectively. For all three concentrations, the model parameters were similar, except the values for D had to be changed in order to obtain a better fitting of the experimental data. Compared to the fitting parameters in the Table 1 obtained for the thermodynamic equilibrium, the values corresponding to the kinetics in Table 8 and Table S2 are similar.

Table 8. Parameter values obtained by fitting the Frumkin adsorption model Equations (1)-(3) and the diffusion Equation (6) to the experimental data of Figure 8 as measured for equimolar solutions of $\mathrm{NaC}_{12} \mathrm{SO}_{4}+\mathrm{C}_{16} \mathrm{TAB}$.

\begin{tabular}{cccccc}
\hline $\mathbf{c}[\mathbf{m o l} / \mathrm{L}]$ & $\mathbf{b}\left[\mathbf{m}^{\mathbf{3}} / \mathbf{m o l}\right]$ & $\boldsymbol{\omega}_{\mathbf{0}}\left[\mathrm{m}^{2} / \mathbf{m o l}\right]$ & $\mathbf{a}$ & $\mathcal{\varepsilon}[\mathbf{m} / \mathbf{m N}]$ & $\mathbf{D}\left[\mathbf{m}^{2} / \mathbf{s}\right]$ \\
\hline $8.00 \times 10^{-7}$ & $1.50 \times 10^{4}$ & $3.80 \times 10^{5}$ & 0.20 & 0.005 & $4.00 \times 10^{-10}$ \\
$1.00 \times 10^{-6}$ & $1.50 \times 10^{4}$ & $3.20 \times 10^{5}$ & 0 & 0.005 & $9.00 \times 10^{-10}$ \\
$3.00 \times 10^{-6}$ & $1.50 \times 10^{4}$ & $3.80 \times 10^{5}$ & 0.20 & 0.005 & $2.50 \times 10^{-10}$ \\
\hline
\end{tabular}

The curves in Figure 9 show a rather fast adsorption kinetics. The $\mathrm{NaC}_{12} \mathrm{SO}_{4}+\mathrm{C}_{6} \mathrm{TAB}$ dimers in Figure 5 show an adsorption isotherm located almost in the same concentration range as the single $\mathrm{NaC}_{12} \mathrm{SO}_{4}$ surfactant. Hence, the adsorption kinetics of the dimers are expected to be similar to those of the single $\mathrm{NaC}_{12} \mathrm{SO}_{4}$ molecules [33]. Although in Figure 9 we do not have the whole adsorption kinetics dependencies (the data are available from $10 \mathrm{~s}$ on), it was possible to fit them with the Frumkin model as well as the reorientation model. 


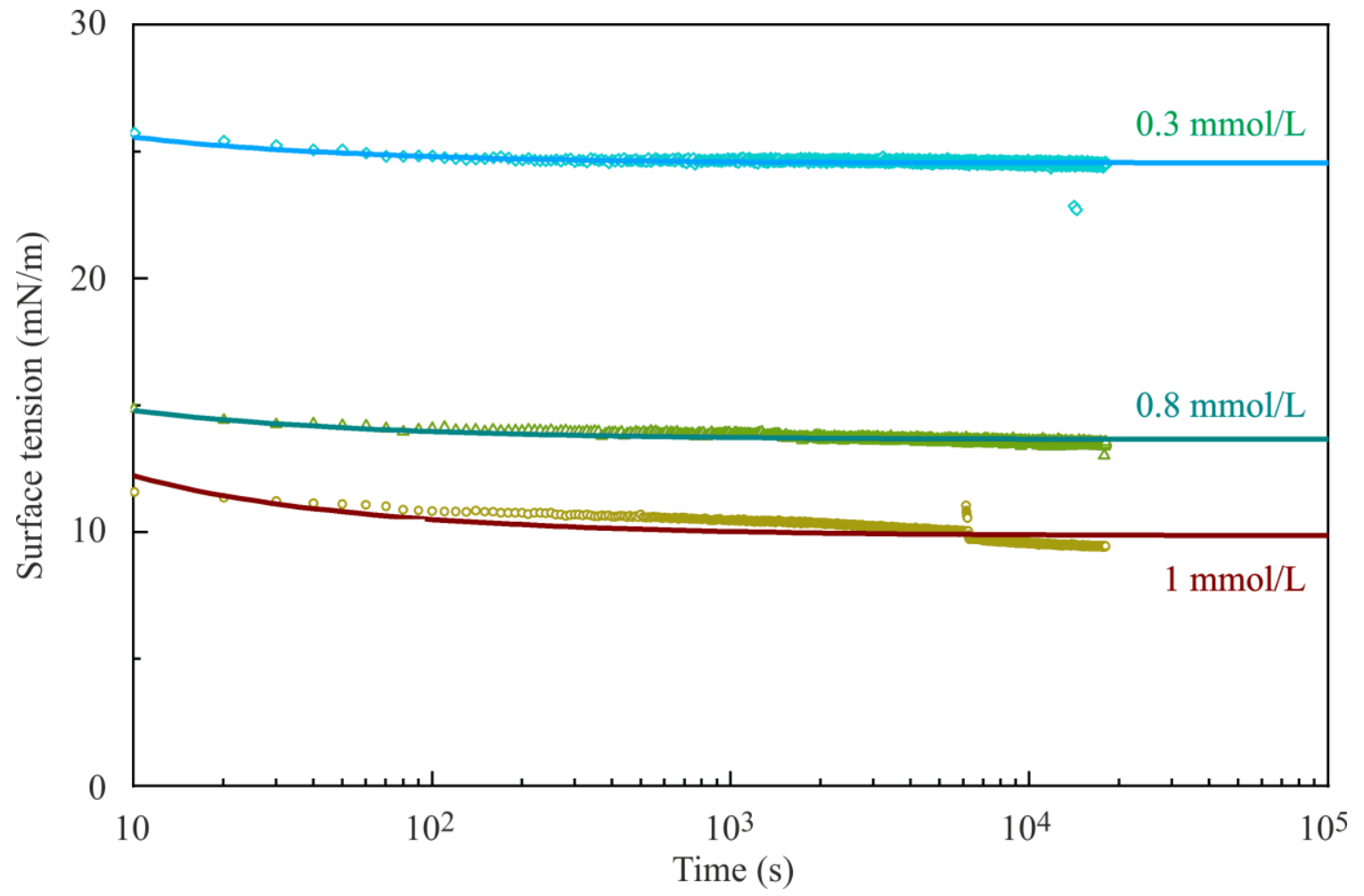

Figure 9. Dynamic interfacial tension of mixed aqueous solutions of $\mathrm{NaC}_{12} \mathrm{SO}_{4}+\mathrm{C}_{6} \mathrm{TAB}$ at the water/hexane interface measured by PAT-1; $(\diamond) 0.3 \mathrm{mmol} / \mathrm{L},(\boldsymbol{\Delta}) 0.8 \mathrm{mmol} / \mathrm{L},(\bullet) 1 \mathrm{mmol} / \mathrm{L}$; solid lines are calculated from the Frumkin and reorientation (see Supplement for the result with the reorientation model) adsorption models, respectively.

The values of the model parameters are listed in Table 9 and Table S3 (see Supplementary Materials). It was not possible to measure the whole kinetic curves due to technical limitations at short adsorption times. Thus, the experimental kinetic curves at short times are systematically missed. As kinetic fitting parameters we used identical values for the model parameter at equilibrium, as shown in Table 3 and only the diffusion coefficients were fitted.

Table 9. Parameter values obtained by fitting the Frumkin adsorption model Equations (1)-(3) and the diffusion Equation (6) to the experimental data of Figure 9 as measured for equimolar solutions of $\mathrm{NaC}_{12} \mathrm{SO}_{4}+\mathrm{C}_{6} \mathrm{TAB}$

\begin{tabular}{cccccc}
\hline $\mathbf{c}[\mathbf{m o l} / \mathrm{L}]$ & $\mathbf{b}\left[\mathbf{m}^{3} / \mathbf{m o l}\right]$ & $\boldsymbol{\omega}_{\mathbf{0}}\left[\mathrm{m}^{2} / \mathbf{m o l}\right]$ & $\mathbf{a}$ & $\mathcal{\varepsilon}[\mathbf{m} / \mathbf{m N}]$ & $\mathbf{D}\left[\mathrm{m}^{2} / \mathbf{s}\right]$ \\
\hline $3.00 \times 10^{-4}$ & $4.30 \times 10^{1}$ & $2.46 \times 10^{5}$ & 0 & 0.005 & $5.00 \times 10^{-10}$ \\
$8.00 \times 10^{-4}$ & $4.30 \times 10^{1}$ & $2.36 \times 10^{5}$ & 0 & 0.005 & $1.00 \times 10^{-10}$ \\
$1.00 \times 10^{-3}$ & $4.30 \times 10^{1}$ & $2.33 \times 10^{5}$ & 0.10 & 0.005 & $2.00 \times 10^{-11}$ \\
\hline
\end{tabular}

In contrast to the experimental results in Figure 9, the experimental points shown in Figure 10 were recorded systematically from about $0.04 \mathrm{~s}$ on, using a capillary pressure tensiometer [34]. Note, as the experimental efforts for such short time interfacial tension measurements is rather time consuming, we did not apply it to the other systems under investigation, as only slightly more experimental data are available in this way. The adsorption kinetics of the catanionic dimers $\mathrm{NaC}_{6} \mathrm{SO}_{4}+\mathrm{C}_{12} \mathrm{TAB}$ show again a very fast adsorption kinetic, similar to the single $\mathrm{C}_{12} \mathrm{TAB}$ molecules [33]. 


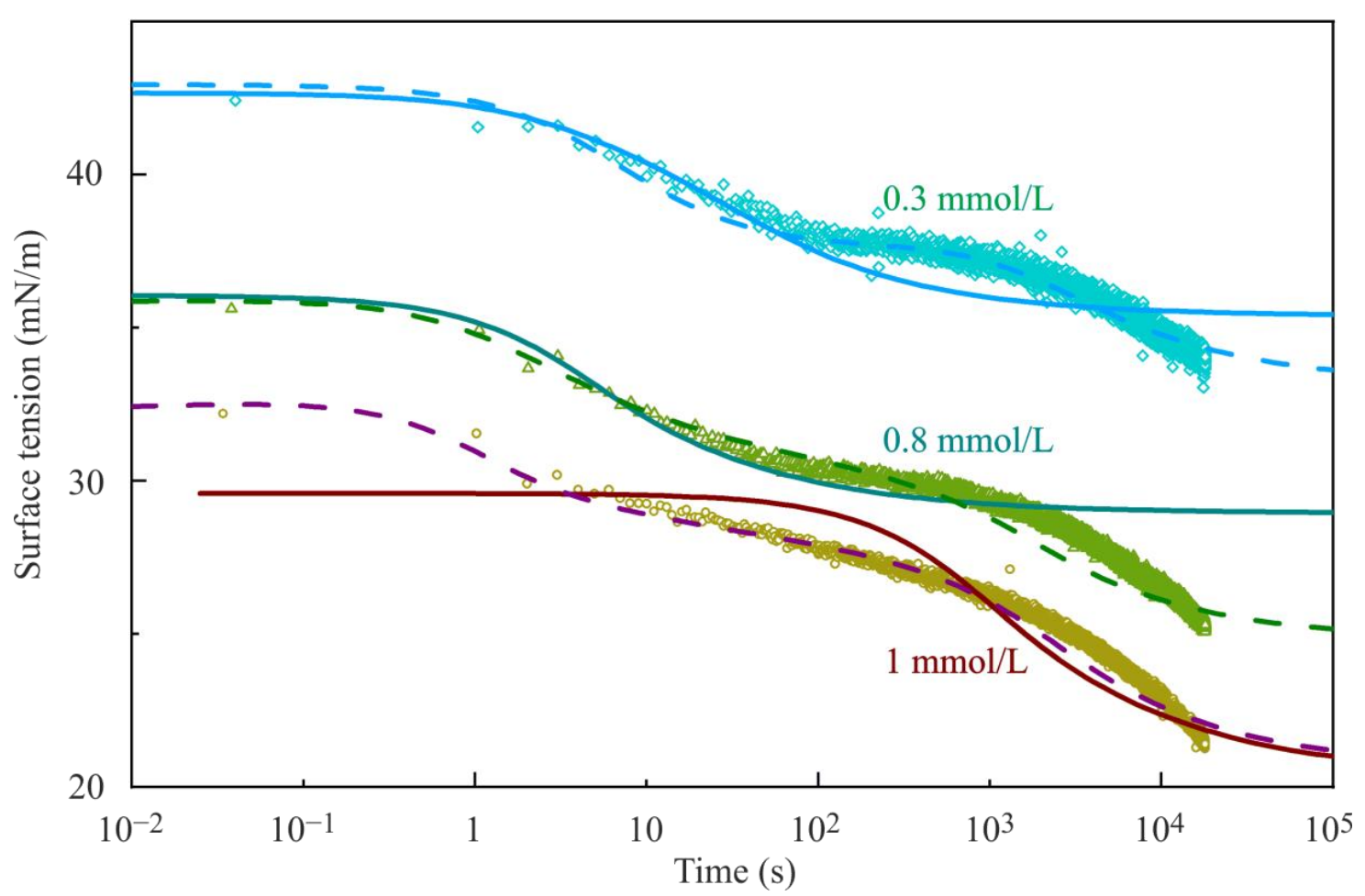

Figure 10. Dynamic interfacial tension of mixed aqueous solutions of $\mathrm{NaC}_{6} \mathrm{SO}_{4}+\mathrm{C}_{12} \mathrm{TAB}$ at the water/hexane interface measured by PAT-1; $(\diamond) 0.3 \mathrm{mmol} / \mathrm{L},(\Delta) 0.8 \mathrm{mmol} / \mathrm{L},(\bullet) 1 \mathrm{mmol} / \mathrm{L}$; solid and dashed lines are calculated from the Frumkin and reorientation adsorption models, respectively.

As one can see in Figure 10, after a first leveling off, a second decrease of the interfacial tension starts. From studies with mixed surfactants we know that this shoulder and the second decrease indicate the presence of a second surfactant compound adsorbing at the interface [6]. At the studied bulk concentrations, we can exclude $\mathrm{NaC}_{6} \mathrm{SO}_{4}$ as this second adsorbing component because it adsorbs only at much higher concentrations. Another option would be the existence of the homologous alcohol of $\mathrm{NaC}_{6} \mathrm{SO} 4$, i.e., hexanol, present as unavoidable impurity in aqueous solution. Hexanol would have a surface activity about 500 time higher than the homologous hexyl sulphate, however, it would not remarkably influence the interfacial tension due to its solubility in the oil phase hexane [35].

Thus, the complex adsorption behavior presented in Figure 10 can refer only to the dimers $\mathrm{NaC}_{6} \mathrm{SO}_{4}+\mathrm{C}_{12} \mathrm{TAB}$ and $\mathrm{C}_{12} \mathrm{TAB}$ as unbound single surfactant with a sufficiently high surface activity as shown in Figure 6 and discussed in [30]. The corresponding parameter values of the two models are summarized in Tables 10 and 11, respectively. Although the system obviously contains two different compounds that adsorb at the interface, we used only a one-component model because the dimers and the single cationic have almost the same surface activity. As one can see, while the Frumkin model does not appropriately describe the experimental curves, the reorientation model does and shows the shoulder and the second decrease in interfacial tension, probably caused by a change in the orientation of the adsorbed molecules.

Table 10. Parameter values obtained by fitting the Frumkin adsorption model Equations (1)-(3) and the diffusion Equation (6) to the experimental data of Figure 10 as measured for equimolar solutions of $\mathrm{NaC}_{6} \mathrm{SO}_{4}+\mathrm{C}_{6} \mathrm{TAB}$.

\begin{tabular}{cccccc}
\hline $\mathbf{c}[\mathbf{m o l} / \mathbf{L}]$ & $\mathbf{b}\left[\mathrm{m}^{3} / \mathbf{m o l}\right]$ & $\boldsymbol{\omega}_{\mathbf{0}}\left[\mathrm{m}^{2} / \mathbf{m o l}\right]$ & $\mathbf{a}$ & $\varepsilon[\mathrm{m} / \mathbf{m N}]$ & $\mathbf{D}\left[\mathrm{m}^{2} / \mathbf{s}\right]$ \\
\hline $3.00 \times 10^{-4}$ & $2.03 \times 10^{1}$ & $3.10 \times 10^{5}$ & 0 & 0.005 & $3.00 \times 10^{-13}$ \\
$8.00 \times 10^{-4}$ & $2.03 \times 10^{1}$ & $2.80 \times 10^{5}$ & 0 & 0.005 & $1.00 \times 10^{-14}$ \\
$1.00 \times 10^{-3}$ & $2.03 \times 10^{1}$ & $2.55 \times 10^{5}$ & 0 & 0.005 & $1.00 \times 10^{-15}$ \\
\hline
\end{tabular}


Table 11. Parameter values obtained by fitting the reorientation adsorption model Equations (4) and (5) and the diffusion Equation (6) to the experimental data of Figure 10 as measured for equimolar solutions of $\mathrm{NaC}_{6} \mathrm{SO}_{4}+\mathrm{C}_{6} \mathrm{TAB}$.

\begin{tabular}{cccccccc}
\hline $\mathbf{c}[\mathbf{m o l} / \mathbf{L}]$ & $\begin{array}{c}\mathbf{b} \\
{\left[\mathbf{m}^{\mathbf{3}} / \mathbf{m o l}\right]}\end{array}$ & $\begin{array}{c}\boldsymbol{\omega}_{\mathbf{1 0}} \\
{\left[\mathbf{m}^{\mathbf{2}} / \mathbf{m o l}\right]}\end{array}$ & $\begin{array}{c}\boldsymbol{\omega}_{\mathbf{2}} \\
{\left[\mathbf{m}^{\mathbf{2}} / \mathbf{m o l}\right]}\end{array}$ & $\boldsymbol{\alpha}$ & $\mathbf{a}$ & $\mathbf{D}_{\mathbf{1}}\left[\mathbf{m}^{\mathbf{2}} \mathbf{s}\right]$ & $\mathbf{D}_{\mathbf{2}}\left[\mathbf{m}^{\mathbf{2}} / \mathbf{s}\right]$ \\
\hline $3.00 \times 10^{-4}$ & $1.50 \times 10^{1}$ & $2.70 \times 10^{5}$ & $1.30 \times 10^{6}$ & 1.40 & 0.20 & $5.00 \times 10^{-10}$ & $1.00 \times 10^{-13}$ \\
$8.00 \times 10^{-4}$ & $1.50 \times 10^{1}$ & $2.70 \times 10^{5}$ & $1.30 \times 10^{6}$ & 1.50 & 0.18 & $2.50 \times 10^{-10}$ & $1.00 \times 10^{-12}$ \\
$1.00 \times 10^{-3}$ & $1.50 \times 10^{1}$ & $2.70 \times 10^{5}$ & $1.30 \times 10^{6}$ & 1.50 & 0.40 & $2.00 \times 10^{-10}$ & $1.00 \times 10^{-12}$ \\
\hline
\end{tabular}

\section{Conclusions}

As continuation of the systematic investigations of catanionic surfactants presented in [30], in this work we studied the influences of the surfactants' molecular geometry on the equilibrium and dynamic interfacial tension at the water/hexane interface. The experimental results were interpreted by two adsorption models (Frumkin and reorientation) combined with a diffusional transport for the kinetics of surfactant adsorption/desorption.

The surfactants studied here have a medium alkyl chain (dodecyl-) mixed with a short alkyl chain (hexyl-) or a long alkyl chain (hexadecyl-) surfactant, respectively. We also investigated the effect of the composition of these catanionics with the same total chain length but composed of surfactants with different alkyl chains, for example $\mathrm{NaC}_{12} \mathrm{SO}_{4}+$ $\mathrm{C}_{16} \mathrm{TAB}$ and $\mathrm{NaC}_{16} \mathrm{SO}_{4}+\mathrm{C}_{12} \mathrm{TAB}$, on the interfacial behavior.

The catanionics consisting of medium and long chain surfactants (dodecyl and hexadecyl) show much higher surface activity than the respective single compounds. The adsorption isotherms are shifted toward lower bulk concentrations of up to three orders of magnitude. In contrast, when mixing surfactants with medium and short chains, the surface activity of the complexes is only slightly increased as compared to the surfactant with the longer chain. The reason for that might be the too low initial bulk concentrations of the single short chain surfactants, which only slightly contributes to the activity of the complex dimers. Moreover, the mutual interactions between the long chain surfactants can squeeze out the short chain surfactants from the adsorption layer [12].

The investigations of the influence of the catanionics' composition with the same total chain length showed that dimers with the same total number of methylene groups have similar adsorption isotherms, although they consist of different single surfactants. However, the polar head of the dimers consist of the same single polar heads, bound to the opposite chains.

The investigations of adsorption kinetics allowed showing that depending on the catanionic complex composition, the molecules show different dynamic properties. For the combination of medium and long chain surfactants (dodecyl and hexadecyl), the adsorption time is significantly decreased as compared with the single surfactants. However, the complexes show a huge decrease in surface tension, due to their significantly increased surface activity.

For the combination of medium and short chain surfactants (dodecyl and hexyl), the adsorption dynamics can show rather complex behaviors, depending on the mutual interactions between the two compounds. Namely, the kinetic curves show a slightly slower surface tension decrease, but also a complex shape of the kinetic curve with a shoulder between two intervals of interfacial tension decrease. This would mean that the interactions of one surfactant with the other play a significant role. In this case, dodecyl chain surfactants squeeze hexyl chain molecules out the adsorption layer, which results in a simultaneous competitive adsorption.

These new aspects in surface and interfacial tension measurements bring new insight into the understanding of surfactants' complexes. This method can be used as a model for investigating surfactant interactions at water/air and water/oil interfaces. By measuring catanionic adsorption properties, we indeed understand the interactions between the individual components. 
Supplementary Materials: The following are available online at https:/ / www.mdpi.com/2504-5 $377 / 5 / 1 / 1 / s 1$, Figure S1: Dynamic interfacial tension of mixed aqueous solutions of $\mathrm{NaC}_{16} \mathrm{SO}_{4}+$ $\mathrm{C}_{12} \mathrm{TAB}$ mixtures at the water/hexane interface measured by PAT- 1 , Table S1: Parameter values obtained by fitting the reorientation adsorption model Equations (4) and (5) and the diffusion equation Equation (6) to the experimental data of Figure S1 as measured for solutions of $\mathrm{NaC}_{16} \mathrm{SO}_{4}+$ $\mathrm{C}_{12} \mathrm{TAB}$, Figure $\mathrm{S} 2$ : Dynamic interfacial tension of mixed aqueous solutions of $\mathrm{NaC}_{12} \mathrm{SO} 4+\mathrm{C}_{16} \mathrm{TAB}$ at the water/hexane interface measured by PAT-1, Table S2: Parameter values obtained by fitting the reorientation adsorption model Equations (4) and (5) and the diffusion equation Equation (6) to the experimental data of Figure $\mathrm{S} 2$ as measured for solutions of $\mathrm{NaC}_{12} \mathrm{SO}_{4}+\mathrm{C}_{16} \mathrm{TAB}$, Figure S3: Dynamic interfacial tension of mixed aqueous solutions of $\mathrm{NaC}_{12} \mathrm{SO}_{4}+\mathrm{C}_{6} \mathrm{TAB}$ mixtures at the water/hexane interface measured by PAT-1, Table S3: Parameter values obtained by fitting the reorientation adsorption model Equations (4) and (5) and the diffusion Equation (6) to the experimental data of Figure $\mathrm{S} 3$ as measured for solutions of $\mathrm{NaC}_{12} \mathrm{SO}_{4}+\mathrm{C}_{6} \mathrm{TAB}$.

Author Contributions: V.B.F., J.K., N.M. and R.M. conceived the study and developed the theory; N.M., J.K., L.P., S.B., and R.M. designed the experiments; E.V.A. developed the fitting software; J.S. performed the experiments; E.S., N.M. and R.M. maintained the experimental tools and contributed materials; N.M.; J.K., E.S., and R.M. wrote the manuscript. All authors have read and agreed to the published version of the manuscript.

Funding: The research was funded by the European Space Agency (MAP project) "Emulsion Dynamics and Droplet Interfaces" and Enviral ${ }^{\circledR}$ Division Additives \& Processes (IAESTE Students Internship Program).

Conflicts of Interest: The authors declare no conflict of interest.

\section{References}

1. Abbott, S. Surfactant Science: Principles E Practice; DEStech Publications, Inc.: Lancaster, PA, USA, 2017 ; ISBN 1605954845.

2. Dickinson, E. Interfacial structure of food emulsions as affected by protein-polysaccharide interactions. Soft Matter 2008, 4, 932-942. [CrossRef]

3. Lawrence, M.J. Surfactant systems-Their use in drug-delivery. Chem. Soc. Rev. 1994, 23, 417-424. [CrossRef]

4. Bramer, T.; Dew, N.; Edsman, K. Pharmaceutical applications for catanionic mixtures. J. Pharm. Pharmacol. 2007, 59, 1319-1334. [CrossRef]

5. Yang, Y.; McClements, D.J. Encapsulation of vitamin E in edible emulsions fabricated using a natural surfactant. Food Hydrocoll. 2013, 30, 712-720. [CrossRef]

6. Fainerman, V.B.; Miller, R.; Aksenenko, E.V. Simple model for prediction of surface tension of mixed surfactant solutions. Adv. Colloid Interface Sci. 2002, 96, 339-359. [CrossRef]

7. Ward, A.F.H.; Tordai, L. Time-dependence of boundary tensions of solutions. J. Phys. Chem. 1946, 14, 453-461. [CrossRef]

8. Miller, R.; Makievski, A.V.; Frese, C.; Krägel, J.; Aksenenko, E.V.; Fainerman, V.B. Adsorption Kinetics of Surfactant Mixtures at the Aqueous Solution-Air Interface. Tenside Surfactants Deterg. 2003, 40, 256-259.

9. Pradines, V.; Lavabre, D.; Micheau, J.C.; Pimienta, V. Determining the association constant and adsorption properties of ion pairs in water by fitting surface tension data. Langmuir 2005, 21, 11167-11172. [CrossRef]

10. Rodakiewicz-Nowak, J. Surface characteristics of some anionic, cationic, and anionic-cationic surfactants. J. Colloid Interface Sci. 1981, 84, 532-535. [CrossRef]

11. Goralczyk, D.; Kita, K. Properties of anionic-cationic adsorption films. Colloids Surf. A 1998, 139, 329-334. [CrossRef]

12. Stocco, A.; Carriere, D.; Cottat, M.; Langevin, D. Interfacial behaviour of catanionic surfactants. Langmuir 2010, 26, 10663-10669. [CrossRef] [PubMed]

13. Liu, Y.-S.; Wen, C.-F.; Yang, Y.-M. Development of ethosome-like catanionic vesicles for dermal drug delivery. J. Taiwan Inst. Chem. Eng. 2012, 43, 830-838. [CrossRef]

14. Jiang, Y.; Li, F.; Luan, Y.; Cao, W.; Ji, W.; Zhao, L.; Zhang, L.; Li, Z. Formation of drug/surfactant catanionic vesicles and their application in sustained drug release. Int. J. Pharm. 2012, 436, 806-814. [CrossRef] [PubMed]

15. Kuo, J.-H.S.; Jan, M.-S.; Chang, C.-H.; Chiu, H.-W.; Li, C.-T. Cytotoxicity characterization of catanionic vesicles in RAW 264.7 murine macrophage-like cells. Colloids Surf. B 2005, 41, 189-196. [CrossRef]

16. Bryant, S.J.; Atkin, R.; Gradzielski, M.; Warr, G.G. Catanionic Surfactant Self-Assembly in Protic Ionic Liquids. J. Phys. Chem. Lett. 2020, 11, 5926-5931. [CrossRef]

17. Yavrukova, V.I.; Radulova, G.M.; Danov, K.D.; Kralchevsky, P.A.; Xu, H.; Ung, W.; Petkov, J.T. Rheology of mixed solutions of sulfonated methyl esters and betaine in relation to the growth of giant micelles and shampoo applications. Adv. Colloid Interface Sci. 2020, 275, 102062. [CrossRef]

18. Elhi, F.; Gantman, M.; Nurk, G.; Schulz, P.S.; Wasserscheid, P.; Aabloo, A.; Põhako-Esko, K. Influence of Carboxylate Anions on Phase Behavior of Choline Ionic Liquid Mixtures. Molecules 2020, 25, 1691. [CrossRef] 
19. Kulbhushan Nandwani, S.; Malek, N.I.; Chakraborty, M.; Gupta, S. Insight into the Application of Surface-Active Ionic Liquids in Surfactant Based Enhanced Oil Recovery Processes-A Guide Leading to Research Advances. Energy Fuels 2020, 34, $6544-6557$. [CrossRef]

20. Loglio, G.; Pandolfini, P.; Liggieri, L.; Makievski, A.V.; Ravera, F. Determination of interfacial properties by the pendant drop tensiometry: Optimisation of experimental and calculation procedures. In Bubble and Drop Interfaces; Miller, R., Liggieri, L., Eds.; Brill Publishers: Leiden, The Netherlands, 2011; Volume 2, pp. 7-38, ISBN 9789004174955.

21. Demond, A.H.; Lindner, A.S. Estimation of interfacial tension between organic liquids and water. Environ. Sci. Technol. 1993, 27, 2318-2331. [CrossRef]

22. Fainerman, V.B.; Aksenenko, E.V.; Kovalchuk, V.I.; Mucic, N.; Javadi, A.; Liggieri, L.; Ravera, F.; Loglio, G.; Makievski, A.V.; Schneck, E.; et al. New view of the adsorption of surfactants a water/alkane interfaces-competitive and cooperative effects of surfactant and alkane molecules. Adv. Colloid Interface Sci. 2020, 279, 102143. [CrossRef]

23. Frumkin, A. Die Kapillarkurve der höheren Fettsäuren und die Zustandsgleichung der Oberflächenschicht. Z. Phys. Chem. 1925, 116, 466-484. [CrossRef]

24. Fainerman, V.B.; Lucassen-Reynders, E.H.; Miller, R. Description of the adsorption behaviour of proteins at water/fluid interfaces in the framework of a two-dimensional solution model. Adv. Colloid Interface Sci. 2003, 106, 237-259. [CrossRef]

25. Fainerman, V.B.; Kovalchuk, V.I.; Aksenenko, E.V.; Michel, M.; Leser, M.E.; Miller, R. Models of two-dimensional solution assuming the internal compressibility of adsorbed molecules: A comparative analysis. J. Phys. Chem. B 2004, 108, 13700-13705. [CrossRef]

26. Miller, R.; Fainerman, V.B.; Aksenenko, E.V.; Leser, M.E.; Michel, M. Dynamic Surface Tension and Adsorption Kinetics od B-Casein at the Solution/Air Interface. Langmuir 2004, 20, 771-777. [CrossRef] [PubMed]

27. Aksenenko, E.V. Studies in Interface Science. In Surfactants-Chemistry, Interfacial Properties and Application; Fainerman, V.B., Möbius, D., Miller, R., Eds.; Elsevier: Amsterdam, The Netherlands, 2001; Volume 13, pp. 619-647, ISBN 0-444-50962-3.

28. Wang, C.; Cao, X.L.; Guo, L.L.; Xu, Z.C.; Zhang, L.; Gong, Q.T.; Zhang, L.; Zhao, S. Effect of molecular structure of catanionic surfactant mixtures on their interfacial properties. Colloids Surf. A Physicochem. Eng. Asp. 2016, 509, 601-612. [CrossRef]

29. Pradines, V.; Fainerman, V.B.; Aksenenko, E.V.; Krägel, J.; Mucic, N.; Miller, R. Adsorption of alkyl trimethylammonium bromides at the water/air and water/hexane interfaces. Colloids Surf. A 2010, 371, 22-28. [CrossRef]

30. Mucic, N.; Gochev, G.; Won, J.; Ulaganathan, V.; Fauser, H.; Javadi, A.; Aksenenko, E.V.; Krägel, J.; Miller, R. Adsorption of Equimolar Aqueous Sodium Dodecyl Sulphate/Dodecyl Trimethylammonium Bromide Mixtures at Solution/Air and Solution/Oil Interfaces. Colloid Polym. Sci. 2015, 293, 3099-3106. [CrossRef]

31. Traube, I. Über die Capillaritätsconstanten organischer Stoffe in wässrigen Lösungen. Justus Liebigs Ann. Chem. 1891, 265, 27-55. [CrossRef]

32. Mucic, N.; Javadi, A.; Kovalchuk, N.M.; Aksenenko, E.V.; Miller, R. Dynamics of interfacial layers-Experimental feasibilities of adsorption kinetics and dilational rheology. Adv. Colloid Interface Sci. 2011, 168, 167-178. [CrossRef]

33. Stubenrauch, C.; Fainerman, V.B.; Aksenenko, E.V.; Miller, R. Adsorption behaviour and dilatational rheology of the cationic alkyl trimethyl ammonium bromides at the water/air interface. J. Phys. Chem. B 2005, 109, 1505-1509. [CrossRef]

34. Javadi, A.; Krägel, J.; Pandolfini, P.; Loglio, G.; Kovalchuk, V.I.; Aksenenko, E.V.; Ravera, F.; Liggieri, L.; Miller, R. Short Time Dynamic Interfacial Tension as Studied by the Growing Drop Capillary Pressure Technique. Colloids Surf. A 2010, 365, 62-69. [CrossRef]

35. Myrick, S.H.; Franses, E.I. Effect of chain length on equilibrium and dynamic surface tension of spread monolayers of aqueous alcohols. Colloids Surf. A 1998, 143, 503-515. [CrossRef] 